why is a method that removes all of it open to condemnation? Clarification will not neutralize the danger of infection that may reside in unpasteurized milk. It is immeasurably superior to the ordinary methods of straining employed on dairy farms. If efficiency in performing this function is to be the measure of condemnation, and if the degree of condemnation is to be proportionate to the legree of efficiency, then the advocates of clarification should be sentenced to service in a diet squad created for the purpose of solving the high cost of living. Clarification (perfect straining) removes all visible sediment. If this is bad practice, why is partial removal by imperfect straining good practice?

Reasoning lackward, all methods of straining should be discontinued, for the more perfect they are, the more repreliensible they become. The covered milk pail should be abolished because it excludes dirt that would be included "under ordinary conditions," and cleansing the cow becomes one of those finicky ideas which, if carried out, prevents the consumer from knowing just how dirty a sample of milk may be "under ordinary conditions." People naturally object to having milk served to them wearing a flowing beard or a toupee or sadly in need of a haircut, and clarification confis. cates all of the hirsute appendages found in milk produced "under ordinary conditions." We might go a step farther and include the cow manure that gave milk its body, bouquet and delectalle flavor in the good old days before dairy inspectors got busy.

Experience has taught me that the happiness of the constmer is not increased when he finds the foreign material that escapes the strainer at the point of production. Following the lead suggested by Professor Hastings, practically every bottle of milk would show visible sediment, little if any of it having any direct effect on health, but a positive effect on appetite, and, therefore, indirectly on health.

Furnishing a safe milk does not, in my humble judgment, end the responsibility of a public health official. It must also make a decent appearance and an appeal to appetite. To fill these requirements, it must be produced in clean dairies by clean milkers, cooled quickly, shipped in sterile containers, pasteurized, clarified and delivered to the consumer in sealed packages.

$$
\text { J. H. LANis, M.D., Health Officer, Cincinnati. }
$$

[Dr. Landis' letter was referred to Professor Hastings, who replies:]

To the Editor:-The rules and regulations which are passed by the health departments of our various governmental units, whether they be municipal, state or federal, should have some actual relation to health problems; whenever a health department is instrumental in the passage of regulations that have no relation to public health it is in truth deceiving the public. It seems to me perfectly true that any city which passes an ordinance requiring the clarification of milk or any health department which passes such a rule is leading the pulblic astray. I should not say that the clarification of milk encourages sloppy methods, but $I$ do think that it may permit the use of methods which could not otherwise be used.

The statement made in the article concerning the cities that have passed ordinances requiring clarification was based on what I supposed to be reliable information. I certainly regret having included Cincinnati in this list since this city has made no such requirement.

I think an inference has been drawn from the article that is not wholly justifiable, namely, that it is a good thing to eliminate a portion of the foreign matter by straining at the point of production. I did not condemn this process because, as it seems to me, it is sucl an ingrained custom of the American farmer that it will be many years before we can hope to prevent him from straining the inilk. I do, however, helieve that if this process could be eliminated it would have an immense value in inducing cleanliness. A beginning is being made in this work. "The inspectors of the New York City Board of Health have found in their work at the various milk receiving stations that the dirt test becomes of little value to them as soon as the farmer applies efficient methods of straining the milk. The officials have apparently begun to consider whetler it would not be a wise thing to prohibit the straining of milk on the farm. For many ycars this has leen a custom in certain of the milk-producing districts of Switzerland, not only for milk that is to be used as market milk, but also for milk to be used in the manufacture of cheese. This custom has been brought to this comntry by some of the Swiss cheese makers. They realize that they can tell far more concerning the methods which the farmer is using in the production of the milk if he does not strain the milk than if he does. I desire to correct the impression which I apparently have made: that I believe that partial removal by imperfect straining of milk is a good practice. I do not think, however, that any city needs to pass an ordinance requiring that the farmers shall strain the milk.

In one other paragraph of Dr. Landis' letter he seems to have confused prevention of the introduction of dirt into milk with its removal. It is well known that the bacteria which are introduced with the mud and manure that get into milk are largely washed from the solid materials with which they were in contact. When these microscopic objects are strained from the milk the bacteria are not likewise removed but remain in the milk. The bacteria are certainly the agents that are instrumental in causing the spoiling of milk, and in many cases influence its healthfulness. The removal of the carrying agent but not the bacteria cannot improve the healthfulness of the milk. I suppose if an agar culture of the typhoid organism were introduced into a vat of milk and allowed to remain until all of the organisms had been washed off and then if the agar on which the bacteria were carried was removed from the milk, we should have something quite comparable to what we actually have in the straining of milk. This certainly would be very different from preventing the introduction of the culture into the milk. The covered milk pail prevents the introduction of dirt with its adherent bacteria. The cleaning of the animal and every other process that prevents the introduction of foreign matter into the milk are certainly to be recommended, but the removal of what we may call the inert agent and leaving the active agent behind can be of little value to the milk consumer other than from purely esthetic grounds.

The largest milk company in the state of Wisconsin has been and still is, I believe, using a very simple straining device. This device costs the company but little to make and nothing for its operation. It apparently does for this company what very much more expensive processes are doing for other companies, and it enables that company to handle milk at a lower margin than would otherwise be the case. It certainly shows that clarification of milk is not an essential factor in the happiness of the consumer.

E. G. Hastings, Madison, Wis.

\section{Why I Do Not Favor Compulsory Health Insurance}

To the Editor:-I do not favor compulsory health insurance:

1. Because it would destroy the personal relations that have always existed between physician and patient.

2. Because it would reduce the rank and file of a learned and respected profession to the level of wage earners.

3. Because it is nothing more or less than lodge or contract practice on a universal scale, and this has proved by experience to be an unmitigated evil; unsatisfactory from the standpoint of both physician and patient.

4. Because, specious arguments of its advocates notwithstanding, compulsory health insurance has not been the means of lowering the mortality rate of any country in the world, for it has been reduced as greatly in those countries that have no state or industrial insurance system as it has been in those that have compulsory health insurance.

5. Because it is pure socialism, and if such medical service is enforced by laws there is no reason why we should not have compulsory insurance for feeding, clothing, sheltering and providing employment for the same classes, as their health depends as much on proper feeding, clothing, shelter and employment as it does on proper medical attention.

6. Because the problems that have given rise to the agitation for compulsory health insurance are not medical problems at 
all, lut purely economic ones, and with a living wage paid by employers to the workers they will be satisfied, and in a position to pay their own bills, medical and otherwise, without aid from the state or any other source.

7. Because it is complicated, adjusted to the peculiarities of European conditions, and would be practically impossible to harmonize with American institutions and ideals.

8. Because the rank and file of the medical profession, reduced from an independent position to the condition of employees working for a corporation, would be as underpaid and dissatisfied as are other wage earners, and this state of affairs would not conduce to the advancement of medicine or redound to the benefit of those under their care.

9. Because the healthy rivalry now existing among physicians to give increasingly efficient service to their patients in order to gain and to hold practice would cease, as no physician would gain anything by increasing his efficiency.

10. Because the meetings of medical societies now devoted to the discussion of scientific subjects would become sessions of debate concerning matters pertaining to the workings of compulsory health insurance to the exclusion of those scientific subjects, the undisturbed consideration of which is necessary for our advancement and learning.

11. Because neither capital, organized labor, the state nor the medical profession desire to have a revolutionary upheaval at the present time, or in fact at any time.

12. Because it would enslave, burden and belittle all parties to it, especially the wage earner and the physician, would completely commercialize the latter, and ring the death knell of medicine as a humanitarian calling.

13. Because it would be a nightmare with no awakening.

14. Because, from the standpoint of sentiment in the United States of America, it is a fad of the hour, akin to universal twilight sleep, the setting of the clock an hour ahead, and other sick minded efforts to change the things that are.

15. Because nobody really wants it, it being a self-evident fact that, like everything else, cheapening medical service means lowering its quality, and no person in this country need suffer from lack of medical attention and care, as those too poor or too improvident to pay are at all times accommodated in hospitals or other institutions; and because compulsory health insurance does not in Europe, and cannot here, either prevent disease or accident or drive a lazy, malingering or chronically sick individual to work.

RAlph S. Cone, M.D., Westwood, N. J.

\section{Queries and Minor Notes}

Anonymous Communications and querics on postal cards will not be noticed. Every letter must contain the writer's name and address, but these will be omitted, on request.

\section{INSTRUCTION IN FIRST AID}

To the Editor. - If you have a manual suitable for the use of a first aid class, kindly send the a copy on approval.

Cimarlotte B. Gardner, M.D., Cumberland, Md.

To the Editor.-Have you any articles or booklets which would be suitable to use in instructing, through lectures and demonstrations, a large class of women in first aid? If you do not publish any, will you refer me to some that are approved for such use by the Americnn Medical Association?

Eva M. Locke, M.D., Nashua, N. H.

ANSwer.-The American National Red Cross publishes a woman's edition First Aid book, price, 30 cents, which can be secured from most booksellers, and which is used as a textbook in connection with courses in First Aid to the Injured by the American Red Cross. When instructing men it is requested that particular attention be given litter bearer work and other transportation methods in order that they may, after taking the First Aid course, be partially prepared for service in any Red Cross organizations that may be formed for the purpose of assisting the armed forces of the United States in time of war.
The First Aid course for women is intended only to teach them what they can do when accidents and sudden illnesses occur within their own homes or elsewhere, and is not, except that they have added to their general information, expected to qualify or accepted as qualifying them for service with the Red Cross in time of war. Women who desire to prepare themselves for war service should write to the "Division of Instruction for Women" of the American Red Cross, Washington, D. C., which offers courses in "Elementary Hygiene and Home Care of the Sick," "Dietetics" and "Preparation of Surgical Dressings."

While it is recommended that women take instruction in First Aid with the belief that it will be a valuable asset to them in their everyday lives, the American Red Cross states that such instruction does not fit them for service in time of war because the Red Cross is not, except in great emergency, allowed to operate in the zone of the advance (front).

The following has been suggested as a series of lectures on First Aid:

1. Shock, use of bandages, triangular bandnge, four tail bandage, etc.

2. liractures.

3. Jiractures and revicw of previous work.

4. Wounds.

5. Bleeding and review of previous work.

6. Insensibility and poisoning.

7. Drowning, choking, etc.; artifictial respiration.

8. Review.

9. Removal of patient; home preparations.

10. Revicw.

11. Examination.

One and one half hours is devoted to each subject. A lecture is given which is usually followed by practical demonstrations in which one member of the class uses another as a patient. The practical work is thus linked with the theoretical.

\section{VENEREAL PROPIIYLAXIS UNIT}

To the Editor:-Where can I find a description for the preparation of a venereal prophylaxis as is used in the Army?

H. H. FARKAS, M.D., York, Pa.

Answer.-According to the manual for the Medical Department of the Army, 1916, the venercal prophylaxis unit contains the following articles:

3 enamel-ware basins
200 sheets form 77 , medical department

1 glass graduate, $120 \mathrm{c} . \mathrm{c}$

350 tablets hydrargyri chloridum corrosivum; 1 tablet in 500 c.c. of water makes a $1: 1,000$ solution

200 ampules of protargol, $2 \mathrm{gm}$, in an ampule.

2 cakes Ivory son!

4 boxes gauze sponges, 1 dozen in a box

4 penis syringes

12 hand towels

4 bottles inguentum hydrargyri chloridi mitis, 30 per cent., $1 / 2$ poutsi in each bottle.

This is packed in a pine box with a hinged lid. The weight of the outfit is 45 pounds. A list of contents and directions for administering the prophylactic treatment are pasted on the inside of the cover.

One outfit of this character is supplied to each evacuation hospital, base hospital or medical reserve unit. A medical reserve unit is a collection of medical supplies which it is estimated will meet the immediate requirements of a reserve for one infantry division.

\section{VALUE OF "STERLING VIOLET RAY GENERATOR" IN} THERAPEUTICS

To the Editor:-I am curious to learn the value of the violet ray in the treate in Canada at the present time in various towns. It is well advertised, not in the same way as a "patent medicinc" would be, but as a genuine form of trcatment. The cnclosed booklet gives a brief outline of what the agents for the "Sterling Violet Ray Generator" claim it will do. The reason I am troubling you about this matter is that I feel if there is anything in it as is claimed, it should be better known. It also seems that if this treatment is not capable of doing what is claimed for it, it is a rather serious thing for a person who may defer calling a physician.

J. A. G.

Answer.-The "Sterling Violet Ray Generator" is a small high frequency apparatus with some vacuum and possibly other electrodes. There is a violet color in these vacuum electrodes when they are energized. The apparatus is not one for producing violet or ultraviolet rays in the scientific meaning of those words. The apparatus certainly will not do the things claimed for it in the booklet which include the treatment of practically eqery ailment known to mankind. 